Title: Location, Location, Location: Presenting evidence for genetically modified crops.

Stephen Morse

Centre for Environmental Strategy,

University of Surrey

Guildford

Surrey GU2 7XH

Telephone +44 (0) 1483686079

Fax $+44(0) 1483686671$

Email: s.morse@surrey.ac.uk

\title{
Clive Evans
}

Department of Geography and Environmental Science, Whiteknights, University of Reading, Reading RG6 6AB, UK

Tel. +44 (0) 1183786260

Fax +44(0) 1189755865

Email: c.w.evans@pgr.reading.ac.uk

Antoinette M. Mannion

Department of Geography and Environmental Science, Whiteknights, University of Reading, Reading RG6 6AB, UK

Tel. +44 (0) 1183786553

Fax +44(0) 1189755865

Email: a.m.mannion@reading.ac.uk 


\begin{abstract}
This paper describes the results of a literature survey to determine the most common methods of analysis and measures of data location employed in journal papers that explore the agronomic and economic differences between genetically modified (GM) and non-GM crop varieties. A total of 108 articles were reviewed and the most common measure of location employed was the arithmetic mean. Only a small minority of articles employed the median or stated that the data had been tested for normality. Yet the choice of measure of location can make a difference in terms of presenting differences between GM and non-GM to a readership. This is illustrated using data from one of the first field-level studies of GM crops in Africa (GM cotton in Makhathini Flats, South Africa), where the median actually gave a greater percentage yield advantage for GM over non-GM cotton than did the mean. However while the median could be justified in statistical terms this could be a source of suspicion amongst those who are opponents of GM.
\end{abstract}

Key words: genetic modification; South Africa; India; literature review; crops; measure of location 


\section{Introduction}

Genetically modified (GM) or engineered crops are those whose genes have been altered by the introduction of foreign DNA (transgenic) to either enhance a pre-existing trait or to express new traits such as insect resistance. . Herbicide tolerant (HT) soybean was the first GM variety of a staple crop to be approved commercially in 1994 (USA; Carpenter and Gianessi, 1999), and by 2010 some $90 \%$ of the US soybean acreage was HT. Insect resistant GM crops were first introduced to the USA in 1996 with the introduction of Delta and Pine Land's Bollgard cotton. The technology has been strongly differentiated in terms of geography. The first African country to approve GM crops was South Africa where Bt cotton was introduced in 1998 (Ismael et al., 2002; Bennett et al. 2006). Asian countries including India and China introduced GM crops soon afterwards. Planting of GM crops has increased substantially since 1996, and according to James (2010) GM crops were grown on 148 million ha in 2009, an 87 fold increase from 1996 which makes "biotech crops the fastest adopted crop technology in the history of modern agriculture" (James 2010, Executive Summary page1). Most of this increase has been in North America, South America and Asia, especially in China while there has been virtually no planting of GM crops in Europe. Indeed the debate over GM crops has polarized between those who urge adoption in order to improve global food production in a warming world with a rapidly increasing population and those who shun such varieties as a potential cause of environmental damage and human health issues (Fukuda-Parr 2006; Thomson 2006; Mannion 2007; Murphy 2007). The debate has resulted in entrenched positions and numerous claims and counter-claims and is too extensive to summarise here. Some recent publications that summarise the arguments are Herring (2009), McHughen and Wager (2010) and Sierra (2010). 
The economic impact of GM crops for farmers has been an especial focus for research and debate, and a number of recent reviews are available (Qaim, 2009; Smale et al., 2009; Carpenter, 2010; Finger et al., 2011). The reader is also refereed to the annual series of reports written by Graham Brooks and Peter Barfoot (available at the PG Economics website www.pgeconomics.co.uk). Carpenter (2010) reviewed the results of 168 studies reported in 49 publications, and Table 1 is a summary of her findings presented in terms of the statistically significant differences in yield between GM and non-GM varieties for studies in a number of developed and developing countries. Her review suggests that the picture is not a uniform one, and points to an important geographical difference. Carpenter divides the 'GM world' into two broad geographic regions; the developed and the developing worlds. Of 61 published studies for developed countries, 36 showed that there was a statistically significant increase in yield for GM varieties versus non-GM. However of these 61 studies, 18 (30\%) showed that there was no difference in yield and $7(11 \%)$ which concluded that the GM yield was actually lower than that for non-GM. For developing countries the corresponding figures were $88,13(15 \%)$ and $6(7 \%)$. In each case the number of studies reporting a significant yield advantage for GM versus non-GM was in the majority, but the number of studies not showing such an advantage is significant and this is especially so for some countries such as the USA, Spain and South Africa. Indeed how GM and non-GM crop varieties are compared is at the heart of debate. For example, Table 2 presents the average difference in yield of GM relative to non-GM that was recorded for the studies included in the Carpenter (2010) paper. In Table 2 the data are presented in terms of crop and technology (herbicide tolerant and insect resistance) and both the mean difference (\%) as well as maximum, minimum and standard errors for this difference are given. Thus Table 2 is deeply imbued with comparisons; between GM and non-GM, between GM traits and between socio-economically constructed regions of the world. Table 2 encapsulates one of the central aspects of the GM 
debate, namely does it provide benefits compared to what can be achieved via non-GM means? For those who believe that GM is ethically or morally wrong then the answer to this question is immaterial (Winter, 2004; Weaver and Morris, 2005), but for those who at least espouse the need for an evidence-base regarding benefits of GM then the question is a critical one. Indeed this debate moves well beyond the pages of refereed journals. For example, there are the following quotes from national newspapers in the UK published some 5 years ago when the debate was especially fierce:

"There is no evidence that GM crops increase yields, reduce pesticide use or bring any public benefits to society."

Ian Pearson (the UK Science Minister at the time) reported in The Daily Telegraph (London), Sep 23, 2008, page 10

"A regular battleground for both sides is whether GM foods can solve the problem of hunger that affects 850 million people. Anti-GM campaigners point out that there is no evidence GM crops improve yields. They are right; they don't, and there have even been examples of certain crops reducing yields."

Jay Rayner in an article entitled "Focus: Science and food: The war over GM is back. Is the truth any clearer?" The Observer (London); Oct 5, 2008; page 28

Ironically despite the clear statements in these quotes, including one from a Science Minister, that there is an absence of evidence to suggest that GM varieties have a yield advantage over non-GM Carpenter draws upon journal papers published prior to and contemporaneous with these newspaper articles that present evidence for such an advantage! So how can the picture Carpenter paints be so dramatically different to these statements in the popular press? This 
question forms the basis for the discussion set out in this paper, and it has to be noted that it is not a question that has exercised geographers all that much. But geographers with their skills in understanding difference in space (physical and social) do have a role to play.

The paper will first explore the ways in which the differences between GM and non-GM crops are typically portrayed in the academic literature.

$<$ Tables 1 and 2 near here>

\section{Comparing GM and non-GM varieties}

Returning to Table 2 it is noticeable how the percentage increases in yield of GM versus non GM are significantly higher for developing countries than developed, possibly reflecting the lower efficiency of pest control in the former given that good quality pesticides are relatively scarce and expensive both to purchase and apply to crops. The former is obvious but the latter will also include the cost of spraying equipment and labour. It should also be noted that pest pressure tends to be higher in the tropics, where most developing countries are located, than in higher latitudes (Schemske et al., 2009). Indeed the variation in average differences in yield reported within the 'developing country' category is significant, ranging from $16 \%$ to 85\%. Given that the studies included by Carpenter have taken place in different locations (notably nation-states) and at different times then no doubt much of the variation is a reflection of social, economic and environmental factors. These can be diverse in nature and include issues of 'official' (mostly produced by multinational companies such as Monsanto) and 'unofficial' (produced locally, often illegally) GM varieties (Bennett et al. 2005; Herring, 2008) and the fact that farmers who adopt GM, at least in the early days after commercial 
release, are often the most 'efficient' in any case and thus separation of a 'GM effect from 'better farmer effect' can be complex (Crost et al. 2007). There are statistical techniques which can address the latter provided the dataset is of adequate size and quality, but it is not a straightforward task.

A further obvious factor to explain the variation in Table 2 may be differences in methodology for collecting and analysing data. Perhaps surprisingly, given the intensity of the debate hinted at above, there are few published papers which explore the methodological approaches used by researchers when examining the economic benefits of GM crops. Smale et al. (2006) is an exception, and they raised a number of concerns regarding methodologies employed in comparative impact studies between GM and non-GM varieties. For example, the relatively short periods typically employed (usually only a few years) in such studies can be problematic as while a positive gain for GM may be shown over that period critics can readily counter by claiming that the benefits will evaporate over longer periods as markets adjust or with traits such as insect resistance the pests may become 'resistant to the resistance'. These are admittedly complex issues, as new GM varieties appear over time and some of them will have resistance based upon a number of introduced genes rather than just one. Also, in fairness it should be noted that to date there have been few reported examples of 'resistance to the resistance' occurring (please see Gassmann et al, 2011, for a recent example). While more recent studies such as that of Subramanian and Qaim (2010) have explored differences between GM and non-GM over a longer time scale, in this case 6 years for households in rural India, this can still be dismissed by critics as being too short for impacts to be assessed. In addition, the gross margins (revenue - cost) estimated in studies may not always include the full costs of all inputs. For example, the cost to the farmer for labour may not always reflect the true market price of labour due to the use of members of 
the household. The latter were often assumed to be 'free' while in practice there may be opportunity costs associated with the use of household labour. Some studies will include this cost, the Subramanian and Qaim (2010) paper being an example, while others may not. Related to this is the point that studies typically do not reflect the influence that growing GM crops has on household livelihood in general. The argument may be that households are putting scarce resource (notably labour) into growing GM which could be of better use if employed elsewhere i.e. that there is an 'opportunity' cost associated with GM crops. However, this is a complex issues as any time saved in growing GM crops (e.g. less time put into crop protection) could be redeployed into other income generating activities (Morse and Bennett 2008; Subramanian and Qaim, 2009).

In addition to such factors, much can also depend upon how the evidence was analysed, notably the statistical methods used, and assumptions that may have influenced the choice of statistical testing and interpretation (Clarke, 2009). Indeed one factor that has received no attention to date is the ways in which results are summarised and presented. The results of a review of 108 articles which compared the agronomic and economic performance of GM and non-GM varieties are presented as Table 3 . These papers were published in a variety of journals and covered much the same range of countries, crops and technologies as set out in the analysis of Carpenter (2010) summarised as Tables 1 and 2. It should be noted that papers can employ more than one of the approaches so the numbers do not add up to 108. In terms of the numbers being compared within the papers, the vast majority (87) of the articles employed the arithmetic mean while only four used an alternative and only one of these employed the median. The confidence interval and standard deviation were the most popular measures of variation employed in the papers. In terms of statistical tests, the most popular 
were the t-test and ANOVA. Few of the papers (only three) employed non-parametric methods.

The emphasis on the arithmetic mean in these papers is interesting. The arithmetic mean has an obvious appeal in terms of its simplicity and clarity, and was indeed the basis for the comparisons made by Carpenter in Tables 1 and 2. It collapses an extensive and complex dataset into a single value in a way that is intuitively clear, especially to a lay audience. However, it may not always be the most appropriate measure of location and this point can be illustrated with data collected from the Makhathini Flats, South Africa (Ismael et al. 2002; Bennett et al. 2006; Morse and Bennett 2008; Morse and Mannion 2009). The Makhathini studies were the first such farm-level (as distinct from controlled trials) comparisons of GM and non-GM varieties to take place in Africa and the results were published more or less contemporaneously with the statements in the popular press given in the introduction. In the Makhathini studies an insect resistant GM cotton variety was commercially released to smallscale farmers in the late 1990s, and research was conducted to assess the economics of the GM variety relative to the non-GM varieties. Insect pests, especially the bollworm complex (Lepidoptera) are especially damaging to cotton yield both in terms of the amount of cotton harvested but also damage to the quality of the lint. Farmers typically have to spend much money and effort in acquiring and spraying pesticides to control these pests, often up to 12 times or more in a single growing season. The GM cotton variety was engineered for insect resistance by inclusion of genes from a bacterium (Bacillus thuringiensis; Bt), and insect pests, most notably those that attack the cotton bolls, are a major cause of yield reduction in Makhathini. The research made this comparison over three cotton growing seasons (1998/1999, 1999/2000 and 2000/01) and data were collected from Vunisa Cotton, a private commercial company, who were the main supplier of cotton seed and credit to small-scale 
farmers in the region at that time and also the agent for the purchasing of the cotton produced. Hence they maintained a detailed record of all input and output transactions and there was no need to rely on farmer recollection. In common with many of the papers included in Table 3 the main device for making the comparison was the arithmetic mean. A summary of the yield results from the Makhathini studies is shown as Table 4, with GM and non-GM results placed adjacent to each other for each growing season. Generally the pattern over the three seasons suggested a clear yield and gross margin advantage for the GM cotton versus the non-GM varieties, much in line with many of the studies reported by Carpenter (2010) of which the Makhathini work represented a sub-set.

<Tables 3 and 4 near here>

However, if the distribution of the raw data is skewed or if there are outliers, these can have the effect of pulling the mean away from the centre of the distribution and thereby making it a less effective measurement of location. Table 4 also shows the measures of skewness (S) and kurtosis (K) for the Makhathini data. For a normal distribution to be reasonably assumed to exist the value of $\mathrm{S}$ must be zero (or close to it) and the value of $\mathrm{K}$ should be approximately 3. As Table 4 shows the realised values for $\mathrm{S}$ and $\mathrm{K}$ were far from these and this suggests that the data were not normally distributed. This can often be the case with crop yield, especially with yields recorded by small-scale farmers in developing countries limited in terms of their input use. Hence there may be many farmers recording very little or indeed no yield while only a small number may have relatively high yields; as indeed was the case with the Makhathini sample. While this is far from being an unusual occurrence the application of statistical tests such as the t-test and ANOVA to such data can be problematic, as such tests do assume normality. Yet only 3 of the 108 GM versus non-GM papers formally 
reported testing for normality. One approach to dealing with non-normality in data is to transform them, for example by using logarithms, before analysis using a parametric technique (Sookoian et al. 2008). But this doesn't always succeed. The results of testing for S and $\mathrm{K}$ for the Makhathini data transformed by taking $\operatorname{logarithm}\left(\mathrm{z}=\log _{\mathrm{e}}(\mathrm{x}+1)\right)$ are also shown in Table 4. While the skew for the transformed data has been significantly reduced for a number of the categories so has the kurtosis (distribution has become flatter). The result of this may be that the transformed data are no closer to normality, although for tests such as the t-test a reduction in skew does help with making the test more applicable (Sookoian et al., 2008). There is a further complication in that strictly speaking the means of transformed data have to be back-transformed by reversing the transformation process. Thus in the case of the logarithmic transformation mentioned above the back-transformation is given by $\mathrm{x}=\mathrm{e}^{\mathrm{z}}-1$

The back-transformed means are also shown in Table 4. While this may be a correct process in statistical terms the dilemma is that it is not so clear to a non-specialist and can appear to be a process of 'data manipulation' and thus result in some suspicion. Interestingly only 6 of the 108 papers reviewed clearly reported the use of a transformation, yet many of these papers were based upon data collected from small-scale farmers.

Alternative non-parametric tests which do not assume normality, such as the Kruskal-Wallis (KW) test (Kruskal and Wallis, 1952), may also be applied to such data. Non-parametric tests have existed for some time and an early review is provided by Siegel (1957). KW tests whether two or more independent samples come from identical populations and thus is a nonparametric alternative to a one-way ANOVA. The KW test is performed on ranks of the original data rather than the data, with the smallest value receiving a rank of 1 , the next smallest gets a rank of 2 and so on. The mean ranking of the categories is then compared. The 
categories of data (e.g. GM and non-GM) can have identical means and medians but still be significantly different when the KW test is applied. The advantage of this approach is that the data are not 'altered' so as to fit the assumptions behind the test as is the case with data transformation. While such non-parametric tests would appear to be suitable for studies focussed on resource poor farmers in the developing world where a degree of skewness would be expected it is interesting to note that only 3 of the 108 papers in Table 3 reported using a non-parametric test.

For the Makhathini dataset all of these tests (t-test with or without transformation and the KW test) point towards a statistically significant yield increase for Bt over non-Bt cotton. Clearly in this case the difference in yield between $\mathrm{Bt}$ and non-Bt cotton was so great as to be reflected in all three of the tests applied to the data. Given that this research was published well before 2008 it may seem very much at odds with the quotations given earlier, but it should be noted that there is an important nuance here. The Bt gene does not increase crop yield per se but it does limit losses of yield as a result of pest attack. For the researcher this is an important difference; yield potential is different from realised yield. The Bt gene does not increase yield potential but can enhance realised yield if there is significant pest pressure. As far as the farmer is concerned, of course, it is the realised yield that matters. The effect of the Bt-based resistance to insect pests is an increase in yield relative to the non-GM but if both varieties were grown in an entirely pest-free environment then there may be little, if any difference between them.. Thus the statements given earlier can still be correct despite the evidence summarised by Carpenter (2010) and the results shown in Table 4.

However, while the Makhathini data clearly point to a statistically significant yield advantage for Bt over non-Bt cotton under pest conditions that prevailed on farmers farms at that time 
there is the important issue of presentation of this difference to consider. Indeed given that the Makhathini raw data have a significant skew, the question is much more one of the 'location' that is most appropriate for comparison. The most commonly presented measure of location is the mean, yet for skewed data (as in Table 4) the median is arguably more appropriate. While at heart this choice should be based on the nature of the data distribution it can also have an impact on how the comparison between GM and non-GM is represented. For example, the comparisons with the mean (based on raw data) and median for the Makhathini data are shown in Figure 1a and it should be noted that the 'GM advantage' is quite different depending on the measure of location employed. In absolute terms, the mean yields were higher than the median yields for both Bt and non-Bt in all three seasons. Thus using mean as the measure of 'location' in tables and graphs may over-emphasise the yield. However, the key factor here is the difference between Bt and non-Bt; the 'GM advantage' so to speak. For the means of the raw data the 'GM advantage' was between 56 and $85 \%$, but based upon the median the yield advantage of GM over non-GM cotton was notably higher at between 76 and $122 \%$. There is some overlap in the range of the mean and median of the raw data but if anything the use of the median generates a greater sense of yield advantage for GM relative to non-GM. For a small-scale farming community in the developing world this representation of difference could be significant. Indeed also shown in Table 4 are the means and medians of the gross margin (revenue - totals costs) in South African Rand (SAR) per hectare. While yield is an important variable, for the small-scale farmer the gross margin is critical and farmers generally try to maximise this return wherever possible. In all three seasons the gross margins were significantly higher for the Bt cotton relative to the non-Bt, and the means and medians readily reflect this although the results of normality and statistical tests are not presented for gross margin in Table 4. Also, as with yield, the absolute values for gross margin were higher when represented by the mean than by the median. In two of the 
seasons (1998/99 and 2000/01) the percentage increase in gross margin was greater when based upon the median that it was when the mean was employed. In 2000/01 for example the difference in gross margin when based upon the mean is $258 \%$ while based upon the median it is $1,224 \%$. Given that these farmers sell all of their cotton the difference in gross margin between $\mathrm{Bt}$ and non-Bt is the key indicator for them, more so than yield. For an individual farmer the measure of location is irrelevant. Yet when assessed over a large population the representation of that 'GM advantage' by use of the mean or the median makes a major difference. After all, a difference of $1,224 \%$ based upon the median is impressive and can readily be used by GM proponents to imply how the population is benefitting from GM.

However, it should not be assumed that the use of the mean and median will always generate quite different representations. Table 5 is a summary of a large data set collected for smallscale farmers in Maharashtra (India). The table includes the means and medians for yield, revenue (in this case an imputed variable found by multiplying yield by a constant price), total costs (in this case found by seed cost plus insecticide cost) and gross margin (revenue cost). The results of statistical tests have not been included but as with the Makhathini data the $\mathrm{Bt}$ cotton was significantly higher for all of these variables, so again this is not an issue. Yet in contrast to the Makhathini data for the most part the percentage difference was similar whether based upon the mean or the median.

$<$ Table 5 near here> 


\section{Discussion}

The growing of GM crops around the world is highly contentious and there are polarised views on the actual or potential benefits of the various crops (Hall, 2008; Russell, 2008; Eaton, 2009). Interested groups as well as researchers at both ends of the scale, proponents and antagonists of GM varieties, seek to highlight the data that supports their cause while at the same time attempting to dismiss other studies that provide support for their opponents. The scientific literature and indeed correspondence between researchers does not stand outside of this debate but is very much part of it, a point highlighted only too well in the 'Climategate' episode at the Climatic Research Unit (CRU), University of East Anglia and the lessons about how 'balance' features in press reporting (Cairns, 2010; Nerlich, 2010). CRU is at the forefront in exploring the mechanisms and indeed impacts of human-mediated climate change, and someone was able to access emails written by staff at the CRU where issues of data analysis and presentation were being discussed. Some of the phrases in these emails were interpreted by climate change sceptics as 'data manipulation'. As one writer puts it:

"What is tragically evident is the picture it gives of the CRU scientists hopelessly at sea with the complex computer programmes they had devised to contort their data in the approved direction, more than once expressing their own desperation at how difficult it was to get the desired results." 
Christopher Booker 'Climate change: this is the worst scientific scandal of our generation',

The Telegraph, 28 Nov 2009. His argument is also set out in Booker (2009).

As can be imagined from the above short quotation, statements regarding data 'manipulation' may be quite correct in technical terms but have the 'feel' to one group of data being concocted or contorted to promote a pre-determined stance.

The dilemma with the measures of location presented in Table 4 for the Makhathini data is that they can produce quite different conclusions depending upon which of them is used. All of the measures of location in both Tables 4 (Makhathini) and 5 (Maharashtra) suggested a clear yield advantage for the GM cotton varieties over the non-GM and all of the statistical tests suggested that this difference was significant. Given the GM technology being assessed here (insect resistance) the difference was due to a reduction in yield losses for the $\mathrm{Bt}$ varieties relative to non-Bt and was not an increase in yield per se. Thus critics of the technology are correct in stating that the Bt trait does not increase yield over non-GM; a statement which would appear to a lay person as suggesting that $\mathrm{Bt}$ is of no benefit whatsoever. After all, if it does not increase the yield then what is the point? However of the two measures of location based upon the 'raw' (untransformed) data, the median gave a greater yield advantage for the GM cotton over the non-GM than did the arithmetic mean. This higher yield does translate into a greater monetary (gross margin) advantage for GM cotton, and in absolute terms this is higher when the mean is used but the percentage difference (the key variable) is greater in two of the seasons when the median is employed. However, for critics of GM this choice of the median to assess location, albeit for good technical reasons, could appear to be highly suspicious as the basis for representing 
difference; in effect an attempt to maximise any advantage for GM over non-GM. However, it should be noted that while the median actually gave a greater percentage difference than did the mean for the Makhathini data, this may not always be the case as shown for the Maharashtra data in Table 5.

Given that the Makhathini and Maharashtra datasets are not likely to be unusual in having such a skewed distribution, especially with such agronomic and economic data for smallscale farmers in the developing world, it is perhaps surprising that the mean of the raw data appears to be the dominant statistic employed for GM versus non-GM comparisons in the literature as shown by the analysis in Table 3. More tests for normality and more widespread use of the median and non-parametric statistical techniques might have been expected, yet these have either not been done or not reported. There is no doubt that the mean is a convenient measure of location; it is easy to calculate and is better understood. Indeed in the papers reporting the Maharashtra data the Kruskal-Wallis test was employed to test difference yet it was the means that were used in comparison tables for this very reason. Indeed studies have suggested a much longer historical timeline for the mean compared to the median (Bakker and Gravemeijer, 2006), and this greater intuitive 'feel' for the mean has conceivably contributed to this. The median is not so intuitive even though it is easily described as the 'middle point' of a dataset, a point poignantly made by the biologist Stephen Gould (2004). Appreciating the choice of the median over the mean does require some technical knowledge or indeed trust in those doing the work, and the dilemmas that researchers can get into with statistical analysis is a well-explored topic. An example of the latter is provided by Abelson (1995) within which he sets out an assertion that quantitative terms (as presented in Tables 4 and 5 for example) arguably have more impact than qualitative ones (interviews with the farmers for example regarding their perceptions of the 
GM versus non-GM difference) and that more specific claims such as the 'GM advantage' in percentage terms have greater impact than less specific ones. But herein rests a wider challenge as Priest et al. (2003) have noted in their study of public trust in GM. Indeed these authors ask a key question (page 766):

"How can policy be democratically derived in situations in which the average person, even the well-educated citizen, cannot be expected to keep abreast of the relevant scientific facts?"

Statements in the popular press such as those given earlier which appear to emphatically state that GM crops have no advantage, yield or otherwise, would be influential for the "average person" despite the fact that reviews such as those of James (2010) consistently show that adoption of GM crops on a global scale is increasing. Cynicism has been defined as "low trust, specifically, a pervasive disbelief in the possibility of goodin dealing with others" (Berman, 1997; page 105) and given the cynicism which surrounds GM technology it is perhaps easy to understand why the published reports of GM versus non-GM have relied upon the most straightforward method for comparison. The GM literature that makes such comparisons may not necessarily be unusual in this regard, no doubt similar decisions are made for a wide variety of studies in the social sciences, but the heated nature of the debate does not help.

\section{Conclusion}

There is a substantial literature which seeks to establish the differences in economic and agronomic performance between GM and non-GM crop varieties. This literature spans just 
about every country, developed and developing, where GM crops are grown, and representation of this difference is an important yet underexplored aspect of the debate. Unfortunately the difference can be quite different depending upon whether the mean or the median is employed as the measure of location, and even if the decision is founded upon good technical reasons this could result in claims of distortion. Hence it is important to clearly explain decisions that have been made and the logic behind them, yet a review of the literature which seeks to explore this difference says little about whether tests for normality have been employed prior to analysis and there is little use of the median and non-parametric statistics even though logic suggests that they should have had a much wider applicability. 


\section{References}

Abelson, R.P. (1995). Statistics as principled argument. Eribaum Associates, Mahwah, NJ.

Bakker, A., Gravemeijer, K.P.E. (2006). An historical phenomenology of mean and median. Educational Studies in Mathematics 62, 149-168

Bennett, R., Ismael, Y., Morse, S. (2005). Explaining contradictory evidence regarding impacts of genetically modified crops in developing countries. Varietal performance of transgenic cotton in India Journal of Agricultural Science 143, 35-41

Bennett, R., Morse, S., Ismael, Y. (2006). The Economic Impact of Genetically Modified Cotton on South African Smallholders: Yield, Profit and Health Effects. Journal of Development Studies 42(4), 662-677

Berman, E.M. (1997). Dealing with cynical citizens. Public Administration Review 57(2), $105-112$

Booker, C. (2009). The Real Global Warming Disaster: Is the Obsession with 'Climate Change' Turning Out to be the Most Costly Scientific Blunder in History? Continuum International Publishing Group, London and New York.

Cairns, J. (2010). Communicating the processes of science to the news media, politicians, and the public. Integrated Environmental Assessment and Management 6, 783-784. 
Carpenter, J., Gianessi, L. (1999). Herbicide tolerant soybeans: Why growers are adopting Roundup Ready varieties. AgBioForum 2(2), 65-72

Carpenter, J. (2010). Peer-reviewed surveys indicate positive impact of commercialized GM crops. Nature Biotechnology 18(4), 319-321

Clarke, M. (2009). Reporting Format. In Cooper, H., Hedges, L.V. and Valentine, J.C. (Eds) The Handbook of Research Synthesis and Meta-Analysis, $2^{\text {nd }}$ Edition. Russell Sage Foundation: New York, pp. 521-536

Crost, B., Shankar, B., Bennett, R., Morse, S. (2007). Bias from farmer self-selection in GM crop productivity estimates: evidence from India data. Journal of Agricultural Economics 58, 24-36.

Eaton, E. (2009). Getting behind the grain: The politics of genetic modification on the Canadian Prairies. Antipode 41(2), 256-281.

Finger, R., El Benni, N., Kaphengst, T., Evans, C., Herbert, S., Lehmann, B., Morse, S. and Stupak, N. (2011). A meta-analysis on farm-level costs and benefits of GM crops. Sustainability 3(5), 743-762.

Fukuda-Parr, S. (2006). The Gene Revolution: GM Crops and Unequal Development. Earthscan: London. 
Gassmann A.J., Petzold-Maxwell J.L., Keweshan R.S., Dunbar M.W. (2011) Field-evolved resistance to Bt maize by Western Corn Rootworm. PLoS ONE 6(7), e22629.

Gould S. (2004). The median isn’t the message. Ceylon Medical Journal 49(4), 139-140.

Hall, C. (2008). Identifying farmer attitudes towards genetically modified (GM) crops in Scotland: Are they pro- or anti-GM? Geoforum 39(1), 204-212.

Herring, R. (2008). Whose numbers count?Probing discrepant evidence on transgenic cotton in the Warangal district of India. International Journal of Multiple Research Approaches 2, $145-159$.

Herring, R. (2009). Persistent narratives: Why is the "Failure of Bt Cotton in India" story still with us? AgBioForum 12(1), 14-22.

Ismael, Y., Bennett, R., Morse, S. (2002). Farm-level economic impact of Biotechnology: smallholder Bt cotton farmers in South Africa. Outlook on Agriculture 31(2), 107-111.

James, C. (2010). Global Status of Commercialized Biotech/GM Crops: 2010. International Service for the Acquisition of Agri-Biotech Applications (ISAAA) Brief 42 Available at http://www.isaaa.org/resources/publications/briefs/42/default.asp

Kambhampati, U., Morse, S., Bennett, R. (2006). Farm-level performance of geneticallymodified cotton: A Frontier Analysis of cotton production in Maharashtra. Outlook on Agriculture 35(4), 291-297. 
Kruskal, W.H., Wallis, W.A. (1952). Use of ranks in one-criterion variance analysis. Journal of the American Statistical Association 47(260), 583-621.

Mannion, A.M. (2007). Biotechnology. In Douglas, I., Huggett, R. and Perkins, C. (Eds)

Companion Encyclopedia of Geography. From Local to Global. Volume 1. Routledge: London, pp. 263-277.

McHughen, A., Wager, R. (2010). Popular misconceptions: agricultural biotechnology. New Biotechnology 27(6), 724-728.

Morse, S., Bennett, R.M. (2008). Impact of Bt cotton on farmer livelihoods in South Africa. International Journal of Biotechnology 10(2//3), 224-239.

Morse, S., Mannion, A.M. (2009). Can genetically-modified cotton contribute to sustainable development in Africa? Progress in Development Studies 9(3), 225-247.

Murphy, D. (2007). Plant Breeding and Biotechnology: Societal Context and the Future of Agriculture. Cambridge: Cambridge University Press

Nerlich, B. (2010). 'Climategate': Paradoxical metaphors and political paralysis. Environmental Values 19(4), 419-442. 
Priest, S.H., Bonfadelli, H., Rusanen, M. (2003). The “Trust Gap" Hypothesis: Predicting support for biotechnology across national cultures as a function of trust in actors. Risk Analysis 23(4), 751-766.

Qaim, M. (2009). The economics of genetically modified crops. Annual Review of Resource Economics 1, 665-693.

Russell, A.W. (2008). GMOs and their contexts: A comparison of potential and actual performance of GM crops in a local agricultural setting. Geoforum 39(1), 213-222.

Schemske D.W., Mittelbach G.G., Cornell H.V., Sobel JM and Roy K. (2009). Is there a latitudinal gradient in the importance of biotic interactions? Annual Review of Ecology, Evolution, and Systematics 40, 245-269

Siegel, S. (1957). Nonparametric statistics. The American Statistician 11(3), 13-19

Sierra, L. (2010). Making sense of GM. Outlooks on Pest Management 21(2), 99-100.

Smale, M., Zambrano, P., Cartel, M. (2006). Bales and Balance: A review of the methods used to assess the economic impact of Bt cotton on farmers in developing economies. AgBioForum. 9(3), 195-212

Sookoian, S., Gemma, C., Gianotti, T.F., Burgueno, A., Castano, G., Pirola, C.J. (2008). Genetic variants of Clock transcription factor are associated with individual susceptibility to obesity. American Journal of Clinical Nutrition 87, 1606-1615 
Smale, M., Zambrano, P., Gruère, G., Falck-Zepeda, J., Matuschke, I., Horna, D., Nagarajan, L., Yerramareddy, I., Jones, H. (2009). Measuring the Economic Impacts of Transgenic Crops in Developing Agriculture during the First Decade Approaches, Findings, and Future Directions. IFPRI Food Policy Review 10. Available for download at www.ifpri.org/sites/default/files/pubs/pubs/fpreview/pv10.pdf

Subramanian, A., Qaim, M. (2009). Village-Wide Effects of Agricultural Biotechnology: The Case of Bt Cotton in India. World Development 37(1), 256-267

Subramanian, A., Qaim, M. (2010). The Impact of Bt Cotton on poor households in Rural India. Journal of Development Studies 46(2), 295-311.

Thomson, J. (2006). GM Crops: Unlocking the Potential. CSIRO: Canberra.

Weaver, S.A. and Morris, M.C. (2005). Risks associated with genetic modification: an annotated bibliography of peer reviewed natural science publications. Journal of Agricultural and Environmental Ethics 18, 157-189.

Winter, M. (2004). Geographies of food: agro-food geographies - farming, food and politics. Progress in Human Geography 28(5), 664-670. 
Table 1. Number and direction of results comparing yields of GM crop varieties to those of non-GM, by country (after Carpenter, 2010)

\begin{tabular}{|c|c|c|c|c|}
\hline Country & GM yields are higher than non-GM & No difference & GM yields are lower than non-GM & Total \\
\hline Developed & 36 & 18 & 7 & 61 \\
\hline \multicolumn{5}{|l|}{ Countries } \\
\hline Australia & 0 & 2 & 2 & 4 \\
\hline Canada & 7 & 0 & 1 & 8 \\
\hline Spain & 3 & 6 & 0 & 9 \\
\hline United States & 26 & 10 & 4 & 40 \\
\hline Developing & 88 & 13 & 6 & 107 \\
\hline \multicolumn{5}{|l|}{ Countries } \\
\hline Argentina & 5 & 1 & 0 & 6 \\
\hline China & 15 & 0 & 0 & 15 \\
\hline Colombia & 4 & 1 & 0 & 5 \\
\hline India & 35 & 2 & 6 & 43 \\
\hline Mexico & 2 & 0 & 0 & 2 \\
\hline Philippines & 5 & 2 & 0 & 7 \\
\hline Romania & 2 & 0 & 0 & 2 \\
\hline South Africa & 20 & 7 & 0 & 27 \\
\hline Total & 124 & 32 & 13 & 168 \\
\hline
\end{tabular}


Table 2. Average impact on yield, by GM technology, for developed and developing countries (after Carpenter, 2010)

Difference in yield (\%) between GM and non-GM crops

\begin{tabular}{lccccc}
\hline \multicolumn{1}{c}{ Technology } & $\begin{array}{c}\text { Number of } \\
\text { studies (N) }\end{array}$ & Average & Minimum & Maximum & Standard error \\
\hline Developed countries & & & & & \\
HT cotton & 6 & 0 & -12 & 17 & 3.8 \\
HT soybean & 14 & 7 & 0 & 20 & 1.7 \\
HT and IR cotton & 2 & 3 & -3 & 9 & 1.8 \\
IR corn & 13 & 4 & -3 & 13 & 1.9 \\
IR cotton & 24 & 7 & -8 & 26 & 1.0 \\
All crops/traits & 59 & 6 & -12 & 26 & N/A \\
\hline Developing countries & 1 & 85 & N/A & N/A & 11 \\
HT corn & 3 & 21 & 0 & 35 & 4 \\
HT soybean & 12 & 16 & 0 & 38 & 6.9 \\
IR corn & 9 & 22 & 0 & 62 & 3.5 \\
IR corn (white) & 82 & 30 & -25 & 150 & 2.9 \\
IR cotton & 107 & 29 & -25 & 150 & \\
All crops/traits & & & & & \\
\hline
\end{tabular}

$\mathrm{N} / \mathrm{A}=$ not applicable 
Table 3. Presentational and statistical methods used within articles to analyse and evaluate the differences between GM and non-GM crops. A total of 108 articles on GM crops were analysed to draw up the table.

Methodological/Statistical approach Number of articles which used the approach

\section{Method of data presentation}

Tabular

Graphical

Measures of location

Arithmetic Mean

Geometric Mean

Mode

Median

Comparisons

GM versus non-GM comparison

Year on year comparisons

Measures of variation

Confidence level

Standard Deviation

Variance

Standard Error

Maximum value

Minimum value

6

Statistical tests

Student t-test

F-test (ANOVA)

Anderson-Darling (test for normality)

Data transformed by taking the natural log

Kruskal-Wallis (non-parametric test)

z statistic 
Table 4. Summary of some descriptive statistics for the Makhathini data (South Africa) along with the results of two statistical tests applied to test the difference between GM and non-GM cotton varieties (after Bennett et al., 2006).

$$
1998 / 99 \quad 2000 / 01
$$

\begin{tabular}{|c|c|c|c|c|c|c|c|c|c|c|c|c|}
\hline \multirow[b]{2}{*}{ Statistic } & \multicolumn{2}{|c|}{ Untransformed } & \multicolumn{2}{|c|}{ Back-transformed } & \multicolumn{2}{|c|}{ Untransformed } & \multicolumn{2}{|c|}{ Back-transformed } & \multicolumn{2}{|c|}{ Untransformed } & \multicolumn{2}{|c|}{ Back-transformed } \\
\hline & $\mathrm{Bt}$ & Non-Bt & $\mathrm{Bt}$ & Non-Bt & $\mathrm{Bt}$ & Non-Bt & $\mathrm{Bt}$ & Non-Bt & $\mathrm{Bt}$ & Non-Bt & $\mathrm{Bt}$ & Non-B \\
\hline Sample size $(\mathrm{N})$ & 87 & 1196 & 87 & 1196 & 112 & 329 & 112 & 329 & 245 & 254 & 245 & 254 \\
\hline Mean yield (kg/ha) & 738 & 452 & 558 & 126 & 489 & 264 & 373 & 147 & 783 & 501 & 332 & 103 \\
\hline Median yield (kg/ha) & 601 & 330 & & & 382 & 217 & & & 548 & 247 & & \\
\hline Skew (yield data) & 1.613 & 1.488 & -0.72 & -1.212 & 1.488 & 1.302 & -0.316 & -2.147 & 1.324 & 1.752 & -1.939 & -0.926 \\
\hline Kurtosis (yield data) & 2.756 & 2.315 & 1.033 & -0.056 & 2.747 & 1.956 & -0.296 & 4.479 & 1.348 & 2.265 & 3.264 & -0.542 \\
\hline Jarque-Bera test & $38 * * *$ & $465 * * *$ & $0.385 \mathrm{~ns}$ & $140 * * *$ & $42 * * *$ & $108 * * *$ & $53 * * *$ & $283 * * *$ & $99 * * *$ & $136 * * *$ & $154 * * *$ & $169 * * *$ \\
\hline t-test (unequal variances assumed) & \multicolumn{2}{|c|}{$\mathrm{t}=-4.69 * * *$} & \multicolumn{2}{|c|}{$\mathrm{t}=-13.12 * * *$} & \multicolumn{2}{|c|}{$\mathrm{t}=-6.21 * * *$} & \multicolumn{2}{|c|}{$\mathrm{t}=-8.12 * * *$} & \multicolumn{2}{|c|}{$\mathrm{t}=-4.5 * * *$} & \multicolumn{2}{|c|}{$\mathrm{t}=-5.57 * * *$} \\
\hline Kruskal-Wallis test & \multicolumn{2}{|c|}{$\mathrm{H}=34.64 * * *$} & \multicolumn{2}{|c|}{ N/A } & \multicolumn{2}{|c|}{$\mathrm{H}=43.63 * * *$} & \multicolumn{2}{|c|}{ N/A } & \multicolumn{2}{|c|}{$\mathrm{H}=34.83 * * *$} & \multicolumn{2}{|c|}{ N/A } \\
\hline Mean gross margin (SAR/ha) & 859 & 292 & & & 376 & -11 & & & 992 & 277 & & \\
\hline Median gross margin (SAR/ha) & 569 & 158 & & & 216 & -43 & & & 573 & -51 & & \\
\hline
\end{tabular}

Transformation was via logarithms $\mathrm{z}=\log _{\mathrm{e}}(\mathrm{x}+1)$. The means for 'transformed' data have been presented as 'back transformed'.

For a Normal distribution it is assumed that the skew is equal to 0 and the kurtosis is 3 . The Jarque-Bera (JB) statistic tests for these combined assumptions for normality; $\left.\mathrm{JB}=\mathrm{n}\left(\left(\mathrm{S}^{\wedge} 2\right) / 6\right)+((\mathrm{K}-3) / 24)\right)$. Where $\mathrm{n}$ is sample size, $\mathrm{S}$ is skew and $\mathrm{K}$ is kurtosis. The larger the deviation of the latter two values from 0 and 3 respectively then the greater the value of the JB statistic.

Note in this table how transformation by taking logarithms often reduces the skew (makes it closer to zero) but also reduces kurtosis. Other tests for normality such as the Anderson-Darling test can be distorted by repeat values. This can happen, for example, if a significant number of zeros are reported in the data perhaps as a result of crop failure or failure to harvest. 
The Kruskal-Wallis non-parametric test (Kruskal and Wallis, 1952) checks whether two or more independent samples come from identical populations, and is thus a nonparametric alternative to a one-way ANOVA (or in this case the t-test). The test compares the mean ranking of the categories (not the medians or means of the raw data in the categories) and calculates a statistic referred to as ' $\mathrm{H}$ '. Here the test is based upon an adjustment for ties (all df $=1$ ). 
Table 5. Summary of some descriptive statistics for the Maharashtra State (India) (after Bennett et al., 2006).

\begin{tabular}{lrrr|rrr} 
& \multicolumn{3}{c}{2002} & \multicolumn{3}{c}{2003} \\
& Bt & Non-Bt & \% difference & Bt & Non-Bt & \% difference \\
\hline Sample size (N) & 2,968 & 4,776 & & 790 & 787 & \\
Mean yield (kg/ha) & 2,105 & 1,506 & 40 & 2,249 & 1,382 & 63 \\
Median yield (kg/ha) & 1,977 & 1,483 & 33 & 2,116 & 1,297 & 63 \\
& & & & & & \\
Mean revenue (Rp/ha) & 42,948 & 31,081 & 38 & 56,073 & 34,465 & 63 \\
Median revenue (Rp/ha) & 40,529 & 29,660 & 37 & 53,072 & 32,618 & 63 \\
& & & & & & \\
Mean costs (Rp/ha) & 5,804 & 5,060 & 15 & 5,452 & 5,173 & 5 \\
Median costs (Rp/ha) & 5,980 & 4,769 & 25 & 5,254 & 4,767 & 10 \\
& & & & & & \\
Mean gross margin (Rp/ha) & 36,885 & 25,730 & 43 & 50,903 & 29,420 & 73 \\
Median gross margin (Rp/ha) & 34,808 & 23,978 & 45 & 47,672 & 27,744 & 72 \\
\hline
\end{tabular}


Figure 1. Percentage difference in yield between GM and non-GM cotton varieties based upon the mean and medians of the yield data shown in Tables 4 and 5.

(a) Makhathini

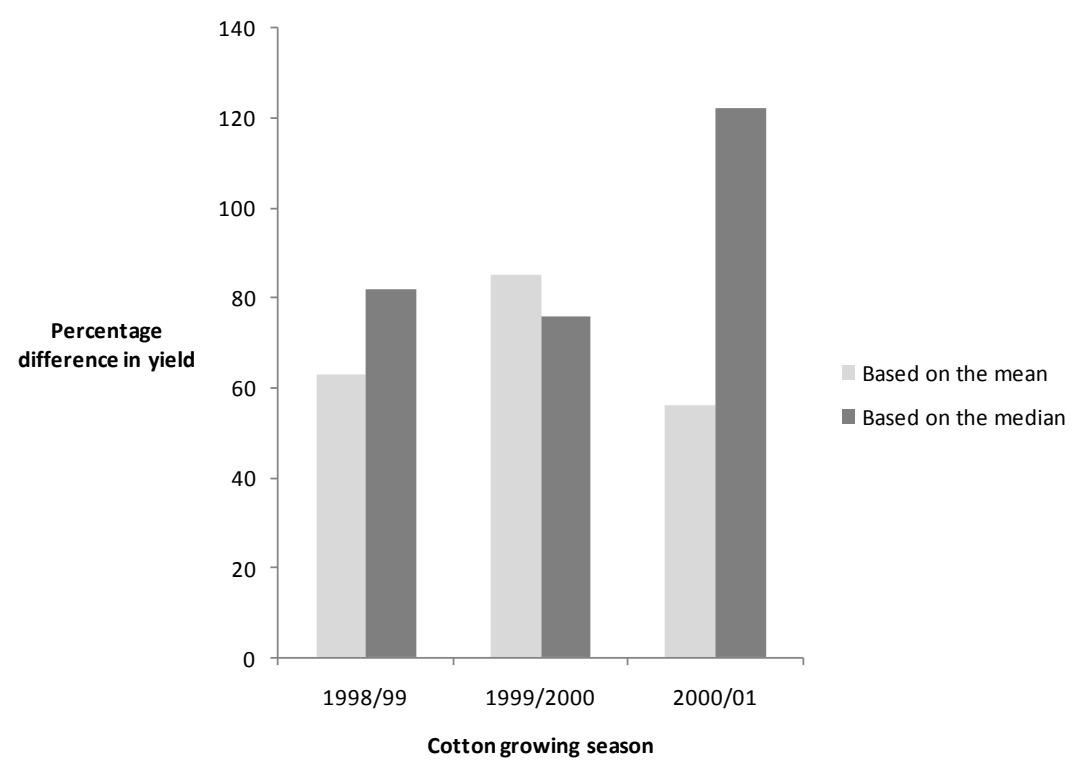

(b) Maharashtra

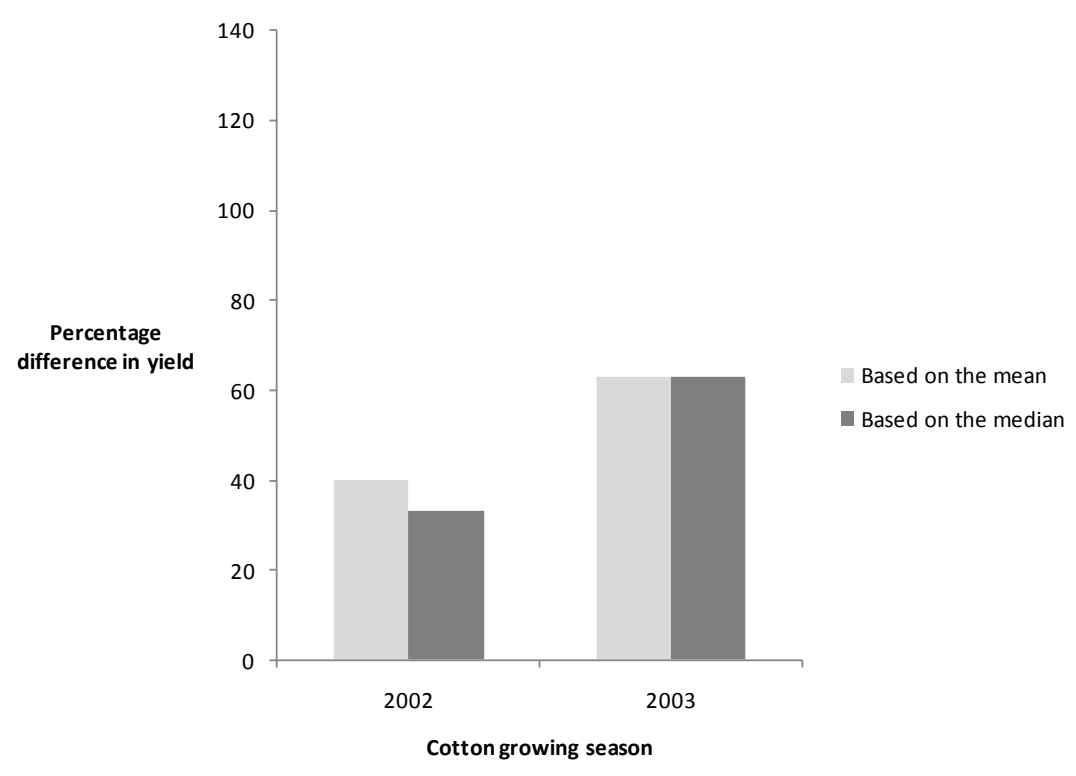

